\title{
Oral doxycycline in the treatment of adult chlamydial ophthalmia
}

\author{
N D VISWALINGAM, S DAROUGAR, AND P YEARSLEY \\ From the External Eye Diseases Clinic, Moorfields Eye Hospital, City Road, London EC1V 2PD, and the \\ Subdepartment of Virology, Institute of Ophthalmology, Judd Street, London WC1H 9 QS.
}

SUMMARY Ninety-three consecutive patients with adult chlamydial ophthalmia were treated with four different regimens of oral doxycycline. In patients treated with a single dose of $5 \mathrm{mg} / \mathrm{kg}$ of body weight $(300 \mathrm{mg})$ of doxycycline the severity of clinical signs was reduced, and in half of the patients shedding of the infective agent was stopped. Treatment with a weekly dose of $300 \mathrm{mg}$ of doxycycline for three weeks or a daily dose of $1.5 \mathrm{mg} / \mathrm{kg}$ of body weight $(100 \mathrm{mg})$ for one week produced a clinical and microbiological cure in $100 \%$ of patients. However, in some of these patients mild to moderate papillary responses were present up to six months from completion of the treatment. The best results were obtained with a daily dose of $100 \mathrm{mg}$ for two weeks, which produced rapid clinical and microbiological cure in all patients.

Adult chlamydial ophthalmia (ACO) or paratrachoma includes inclusion conjunctivitis, TRIC-agent punctate keratoconjunctivitis, and trachoma of sexually transmitted origin.' ACO is generally associated with a concurrent, but mainly asymptomatic, chlamydial genital infection in the patient and/or in the patient's consort(s). ${ }^{23}$ It is estimated that in the developed countries approximately $1 \%$ of the patients with a chlamydial genital infection may develop ACO (unpublished data). However, the prevalence of $\mathrm{ACO}$ is increasing because of the rising prevalence of chlamydial genital infections. ${ }^{4}$

ACO has been shown to respond well to topical treatment with tetracycline or rifampicin eye ointment when used for a minimum period of six weeks. ${ }^{56}$ However, the major setback in this method of therapy is the patient's poor compliance owing to difficulty with correct application of ointment and the long course of treatment. In addition the concurrent genital infection remains untreated, which may cause reinfection of the eye or other severe complications such as endometritis, pelvic inflammatory disease in women, and infertility in men and women. ${ }^{78}$ Oral therapy with systemic tetracycline has been shown to be effective against chlamydial genital infections ${ }^{9}$ and trachoma. ${ }^{10}$

In this report we present the results of an open trial

Correspondence to ND Viswalingam, Subdepartment of Virology, Institute of Ophthalmology, Judd Street, London WC1H 9QS. of the efficacy of various regimens of therapy with oral doxycycline, a long-acting synthetic derivative of tetracycline, in the treatment of ACO.

\section{Patients and methods}

Patients. Patients attending the External Eye Diseases Clinic, Moorfields Eye Hospital, with a moderate or severe follicular conjunctivitis with or without keratitis and with a positive culture test for Chlamydia trachomatis were included. The patients were examined with a Haag-Streit 900 slit-lamp and the symptoms and signs observed in the whole of the conjunctiva (i.e., upper tarsus, upper fornix, and lower lid) and cornea were graded on a 0-3 scale following the method described earlier. ${ }^{5}$ Clinical scores were calculated by adding the individual scores for symptoms and signs from all areas of the conjunctiva and cornea. Patients were considered to be clinically cured when they had a clinical score of less than 10 .

Chlamydial Isolation. Swabbings were collected from the whole conjunctiva and placed in plastic vials containing 2SP transport medium ${ }^{11}$ with $3 \%$ fetal bovine serum. The methods of storage and transport of the conjunctival specimens and culture in irradiated McCoy cells are described elsewhere..$^{12-14}$

Medication. Consecutive patients were treated with doxycycline on one of the following regimens: (a) a single dose of $300 \mathrm{mg}$ ( $5 \mathrm{mg} / \mathrm{kg}$ body weight); 
(b) a weekly dose of $300 \mathrm{mg}$ for three weeks; (c) an initial dose of $300 \mathrm{mg}$ on the first day followed by a daily dose of $100 \mathrm{mg}(1.5 \mathrm{mg} / \mathrm{kg}$ body weight) for one week; (d) an initial dose of $300 \mathrm{mg}$ on the first day followed by a daily dose of $100 \mathrm{mg}$ for two weeks. The patients were advised to take the drug after a meal.

Follow-up. Treatment was begun after the initial clinical and laboratory investigations. Follow-up clinical examinations and culture tests were carried out at weekly intervals for four weeks, then at six weeks, eight weeks, 12 weeks, six months and 12 months.

\section{Results}

Ninety-three consecutive patients with moderate to severe $\mathrm{ACO}$ and a positive culture for $C$. trachomatis were included in this study. The ages of the patients ranged from 16 years to 45 years, the majority being between 18 and 30 years old. There were 47 male and 46 female patients.

Single dose treatment. Eleven patients were treated with a single dose of doxycycline and followed up for eight weeks. Clinically no patient was cured (Table
1), but the intensity of inflammatory responses in all of these patients was substantially reduced (Table 2, Fig. 1). Microbiologically, four of the nine (44\%) patients who attended regularly were culture negative at eight weeks (Table 2). However, because of the continuing presence of active clinical signs and/or positive culture tests, these patients were subsequently treated with $1 \%$ rifampicin eye ointment and were referred to our Genito-Urinary Medicine Clinic for investigation and management of probable chlamydial genital tract infection.

Weekly dose for three weeks. At 12 weeks 17 of the 22 patients treated on this regimen had completed their follow-up examinations. In all these patients clinical and microbiological cures were obtained (Table 1, Figs. 1 and 2). However, 5 of the 17 patients had persistent mild to moderate papillary responses up to six months after completion of treatment. These papillary responses resolved with no further treatment.

Daily dose for one week. All the 12 patients who were followed up at 12 weeks were microbiologically and clinically cured (Table 2; Figs. 1 and 2). Clinically three of the 12 patients showed papillary

Table 1 Number of patients cured following treatment with oral doxycycline

\begin{tabular}{|c|c|c|c|c|c|c|c|}
\hline $\begin{array}{l}\text { Treatment } \\
\text { regimen }\end{array}$ & $\begin{array}{l}\text { No. of } \\
\text { patients }\end{array}$ & $\begin{array}{l}\text { Four weeks } \\
\text { clinical }\end{array}$ & culture* & $\begin{array}{l}\text { Eight weeks } \\
\text { clinical }\end{array}$ & culture $\dagger$ & $\begin{array}{l}12 \text { Weeks } \\
\text { clinical }\end{array}$ & culture $\ddagger$ \\
\hline $\begin{array}{r}\text { Single dose } \\
(300 \mathrm{mg})\end{array}$ & 11 & $0 / 11$ & $\begin{array}{l}5 / 11 \\
(45 \%)\end{array}$ & $0 / 11$ & $\begin{array}{l}4 / 9 \\
(44 \%)\end{array}$ & Not done & Not done \\
\hline $\begin{array}{l}\text { Three weekly doses } \\
(300 \mathrm{mg})\end{array}$ & 22 & $\begin{array}{l}14 / 22 \\
(64 \%)\end{array}$ & $\begin{array}{l}22 / 22 \\
(100 \%)\end{array}$ & $\begin{array}{l}14 / 22 \\
(64 \%)\end{array}$ & $\begin{array}{l}20 / 22 \\
(91 \%)\end{array}$ & $\begin{array}{l}17 / 17 \\
(100 \%)\end{array}$ & $\begin{array}{l}17 / 17 \\
(100 \%)\end{array}$ \\
\hline $\begin{array}{l}\text { One week } \\
\quad(100 \mathrm{mg} \text { daily })\end{array}$ & 15 & $\begin{array}{l}12 / 15 \\
(80 \%)\end{array}$ & $\begin{array}{l}15 / 15 \\
(100 \%)\end{array}$ & $\begin{array}{l}13 / 15 \\
(87 \%)\end{array}$ & $\begin{array}{l}13 / 13 \\
(100 \%)\end{array}$ & $\begin{array}{l}12 / 12 \\
(100 \%)\end{array}$ & $\begin{array}{l}12 / 12 \\
(100 \%)\end{array}$ \\
\hline $\begin{array}{l}\text { Two weeks } \\
\quad(100 \mathrm{mg} \text { daily })\end{array}$ & 45 & $\begin{array}{l}43 / 45 \\
(96 \%)\end{array}$ & $\begin{array}{l}45 / 45 \\
(100 \%)\end{array}$ & $\begin{array}{l}45 / 45 \\
(100 \%)\end{array}$ & $\begin{array}{l}43 / 43 \\
(100 \%)\end{array}$ & $\begin{array}{l}39 / 39 \\
(100 \%)\end{array}$ & $\begin{array}{l}39 / 39 \\
(100 \%)\end{array}$ \\
\hline
\end{tabular}

${ }^{*}$ Four weeks after beginning of treatment.

$\dagger$ Eight weeks after beginning of treatment.

$\ddagger$ Twelve weeks after beginning of treatment.

Table 2 Effect of different treatment regimens on clinical scores and isolation of C. trachomatis

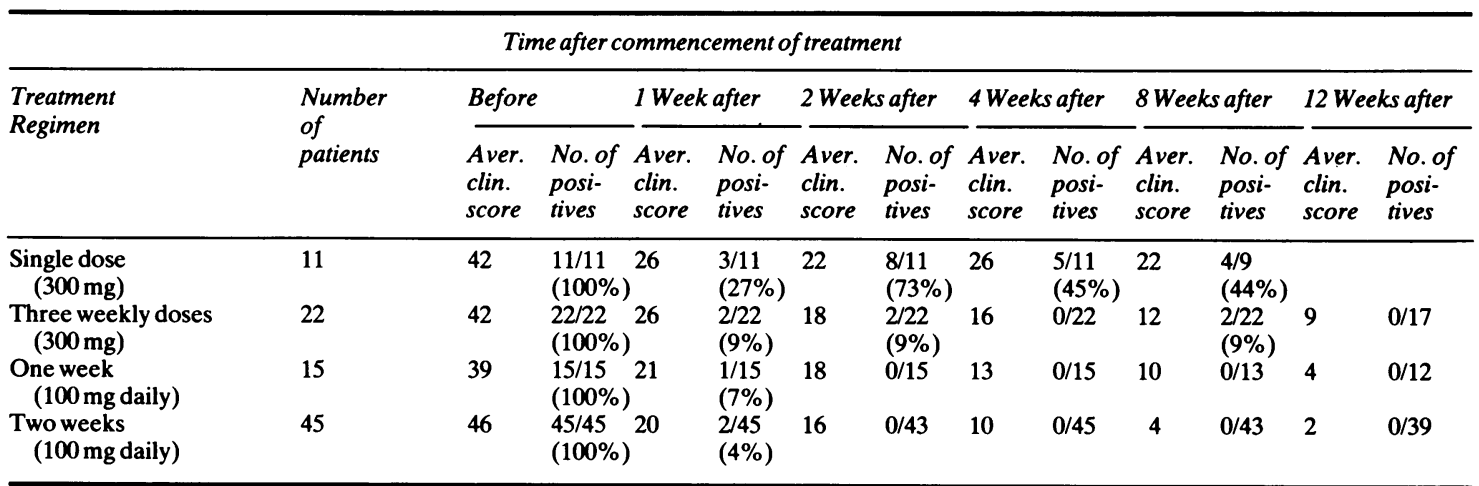

Clinical scores $\leqslant 10$ trivial; $11-20$ mild; $21-30$ moderatc; $31-40$ severe. , 


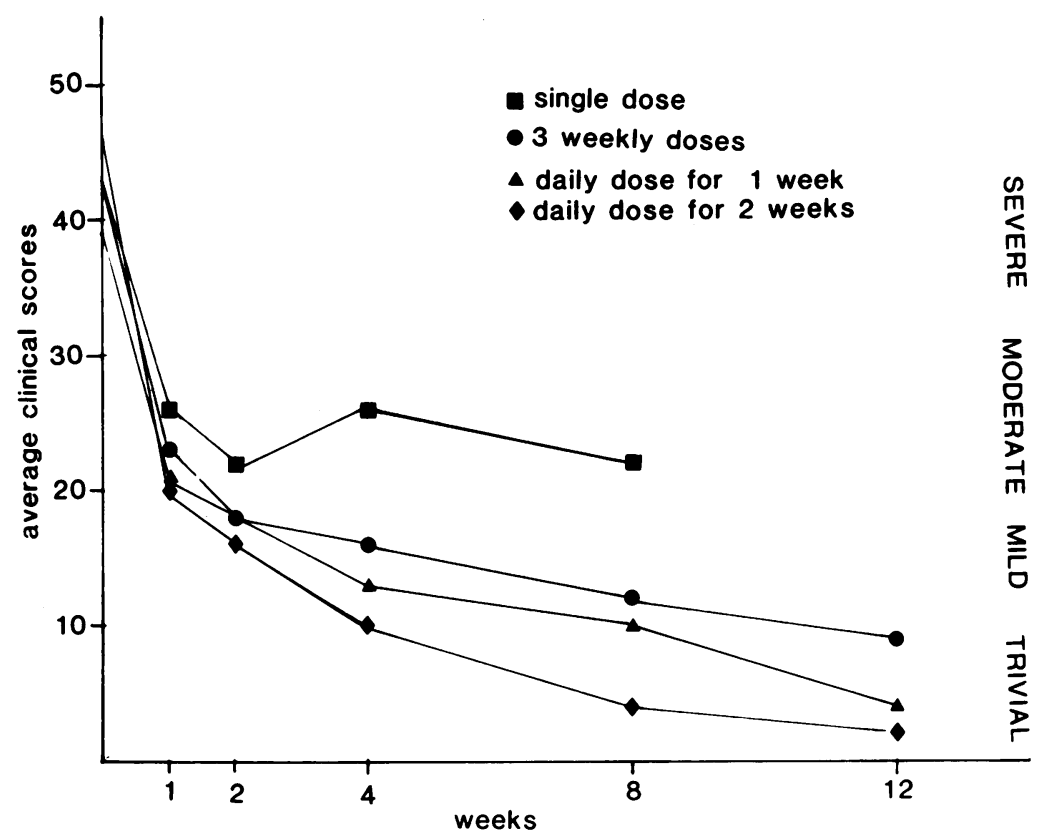

Fig. 1 Clinical response to treatment on various regimens of oral doxycycline.

responses for up to six months after completion of treatment. These papillary responses resolved with no further treatment.

Daily dose for two weeks. All of the 39 patients who were followed up at 12 weeks were clinically and microbiologically cured.

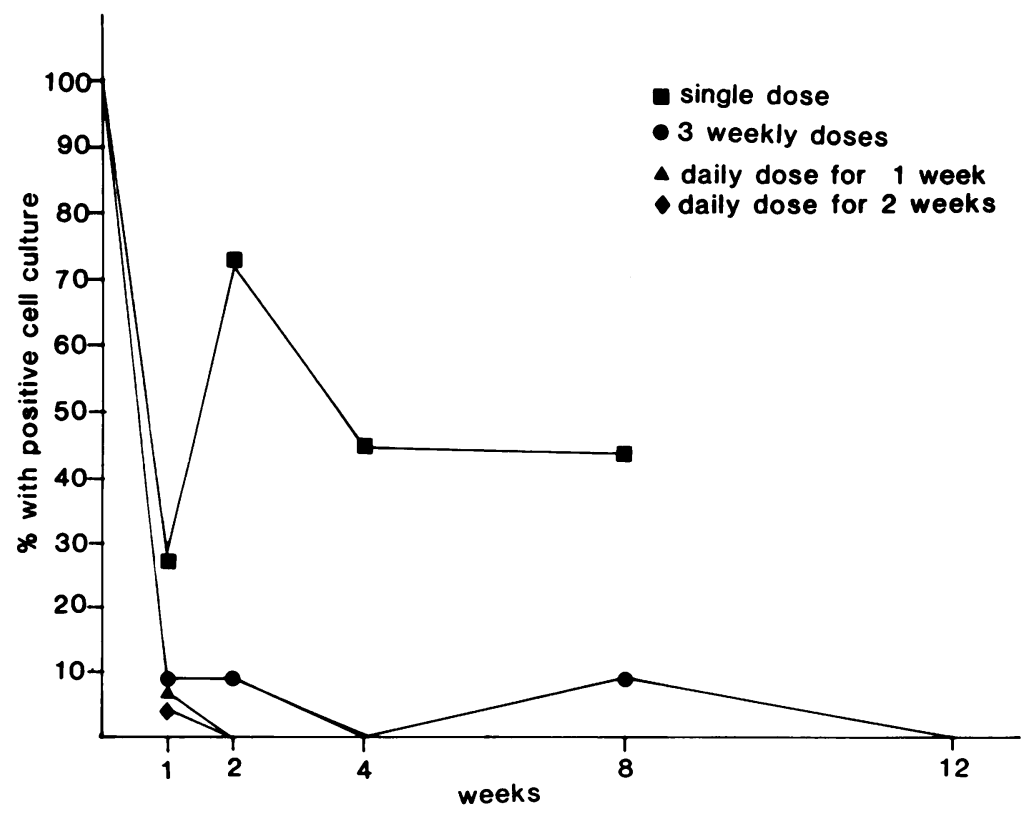

Further follow-up. Further follow-up showed clinical and microbiological cure in those patients who did not attend regularly during the first three months of the study and were not included in the Tables 1 and 2.

Adverse reactions. Two of the 22 patients on
Fig. 2 Microbiological response to treatment on various regimens of oral doxycycline. 
weekly doses for three weeks and three patients who received daily treatment for two weeks complained of nausea or epigastric burning.

\section{Discussion}

This open treatment trial was designed to find the optimal regimen of treatment with doxycycline for patients with ACO. The results showed that a single dose of $300 \mathrm{mg}$ doxycycline reduces the severity of clinical signs and stops the shedding of $C$. trachomatis in about half of the patients. Treatments with a weekly dose for three weeks or a daily dose for one week were equally effective in producing clinical and microbiological cure in all the patients. However, some of these patients showed persistent papillary responses up to six months after completion of treatment, which resolved with no further treatment. The best result, however, was obtained with a daily dose of $100 \mathrm{mg}$ for two weeks, when a rapid resolution of clinical signs was achieved. This finding is consistent with our previous study of treatment of trachoma with doxycycline in a village in Iran. ${ }^{11}$

The advantages of therapy with doxycycline over other tetracyclines are that it requires minimal daily dose schedules, which greatly enhance patient compliance; it is better absorbed from the gut; and absorption is not affected by diet.

In this study we did not investigate the patients for the presence of chlamydial genital infections before the start of treatment. Three months after starting it 56 patients who had been treated with weekly or daily doses of doxycycline attended our Genito-Urinary Medicine Clinic. C. trachomatis was not isolated from specimens taken from the genital tract of any of these patients. In previous studies it had been shown that in untreated women and men with ACO $90 \%$ and $48 \%$ respectively had concomitant microbiologically proved genital chlamydial infections. The failure to isolate $C$. trachomatis from the genital tract of treated patients in this study suggests that oral doxycycline therapy can simultaneously cure both ocular and genital chlamydial infections.

The results of this study indicate that one weekly dose of doxycycline for three weeks, or a daily dose for one week, or a daily dose for two weeks are effective in the treatment of ACO and its associated genital infections. However, treatment with a daily dose of doxycycline for two weeks produced a faster clinical recovery than the other two regimens.

The authors are grateful to colleagues at Moorfields Eye Hospital for referring the patients. The study was supported by a grant from the Department of Health and Social Security through Moorfields Eye Hospital and an anonymous donor.

\section{References}

1 Jones BR. The prevention of blindness from trachoma. Trans Ophthalmol Soc UK 1975; 95: 16-33.

2 Jones BR, Al-Hussaini MK, Dunlop EMC. Genital infection in association with TRIC virus infection of the eye: I. Isolation of virus from urethra, cervix, and eye. Preliminary report. $\mathrm{Br} J$ Vener Dis 1964; 40: 19-24.

3 Dunlop EMC, Jones BR, Al-Hussaini MK. Genital infection in association with TRIC virus infection of the eye: III. Clinical and other findings. Preliminary report. Br J Vener Dis 1964; 40: 33-42.

4 Annual report of the Chief Medical Officer of the Department of Health and Social Security for the year 1983. Sexually transmitted diseases. Br J Vener Dis 1985; 61: 204-7.

5 Darougar S, Viswalingam ND, Treharne JD, Kinnison JR, Jones BR. Treatment of TRIC infection of the eye with rifampicin or chloramphenicol eye ointment. Br J Ophthalmol 1977; 61: 255-9.

6 Darougar S, Viswalingam ND, El-Sheikh H, Hunter PA, Yearsley P. A double-blind comparison of topical therapy of chlamydial ocular infection (TRIC infection) with rifampicin or chlortetracycline. Br J Ophthalmol 1981; 65: 549-52.

7 Ingerslev HJ, Møller BR, Mårdh P-A. In: Mårdh P-A, Møller, BR, Paavonen J, eds. Chlamydia trachomatis in genital and related infections. Stockholm: Almqvist and Wiksell, 1982: 59-63.

8 Westrom L, Mårdh P-A. Chlamydial salpingitis. Br Med Bull 1983; 39: 145-150.

9 Oriel JD, Ridgway GL. Genital infection by Chlamydia trachomatis. In: Curr Top Infect Series 2; 1982: 86-98.

10 Darougar S, Jones BR, Viswalingam N, et al. Family based intermittent therapy of hyperendemic trachoma with topical oxytetracycline or oral doxycycline. Br J Ophthalmol 1980; 64: 291-5.

11 Gordon FB, Harper IA, Quan AL, Treharne JD, Dwyer RStC, Garland JA. Detection of Chlamydia (Bedsonia) in certain infections of man. I. Laboratory procedures: comparison of yolk sac and cell culture for detection and isolation. J Infect Dis 1969; 120: 451-62.

12 Darougar S, Jones BR. Conjunctival swabbing for isolation of TRIC agent $\mathrm{Br}$ J Ophthalmol 1971; 55: 585-90.

13 Darougar S, Kinnison JR, Jones BR. Simplified irradiated McCoy cell culture for isolation of chlamydial, trachoma and related disorders caused by chlamydial agents. In: Nichols RL, ed. Excerpta Medica International Congress Series 1971; 223: 63-70.

14 Darougar S, Jones BR, Kinnison JR, Vaughan-Jackson JD, Dunlop EMC. Chlamydial infection: advances in the diagnostic isolation of chlamydia, including TRIC agent, from the eye, genital tract, and rectum. BrJ Vener Dis 1972; 48: 416-20.

Accepted for publication 29 July 1985. 